\title{
Microstructure and mechanical properties of Argopecten irradians
}

\author{
You. Lv ${ }^{1, \text { a }}$, Li.Qun.Lei ${ }^{2, b}$, Li.Na.Sun ${ }^{3, c}$, Xiu.Fang. Zhang ${ }^{4, d}$, Wen.Cui. Xiu ${ }^{5, e}$ \\ 1,2,3,4,5 School of Mechanical Engineering, Jilin Agriculture Science and Technology College, Jilin \\ City, Jilin Province, 132101, P.R. China
}

aemail:Ilvvyou@163.com, bemail:leiliqun@163.com, cemail:sunlina@163.com, ${ }^{\mathrm{d} e m a i l}$ :zhangxiufang @163,com, eemail:xiuwencui@163.com

Keywords: Mechanical property; Biomaterials; Microstructure; Composite

\begin{abstract}
This paper investigated the microstructure and composition of Argopecten irradians through X-ray diffraction (XRD), field emission scanning electron microscope (FESEM) and energy spectrometer (EDS), and measured the hardness and tribological properties of Argopecten irradians using nanoindentation and friction wear testing machine. The results showed that Argopecten irradians mainly contained carbon, calcium and oxygen, and existed in the mineral phase. There were many radial ribs on the surface of Argopecten irradians shell. The microstructure of Argopecten irradians was crossbedded. The surface hardness and elastic modulus of Argopecten irradians were 0.094 and $5.85 \mathrm{GPa}$, respectively. With an increase in the cross-section distance, the hardness and elastic modulus of Argopecten irradians decreased gradually, and there was an obvious gradient for the mechanical properties. When the temperature was below $200^{\circ} \mathrm{C}$ during heat treatment, the hardness and elastic modulus of Argopecten irradians first changed slightly and then increased gradually. Under water lubrication conditions, the frictional coefficient of Argopecten irradians / silicon nitride friction counterparts was greater than that of the dry friction condition. This research provided the bionic basis for the compressive composite materials and anti-friction surface design.
\end{abstract}

\section{Introduction}

After millions of years of evolution, natural biological materials have formed a special structure, which led to their excellent mechanical properties [1-3]. The research on the structure and mechanical properties of the natural biological materials was very important to the bionic design of materials $[4,5]$. Argopecten irradians shell was approximately circular in shape and white in colour. The radial ribs on the shell surface were wide and high without thorns. It had a small size, light weight and high strength, and presented very strong environmental adaptation ability. The shell life played an important role in the life of Argopecten irradians, and gained better mechanical properties, drag reduction and anti-friction characteristics. This paper studied the structure and mechanical properties of Argopecten irradians, which would be conducive to bionic composite design.

\section{Experimental procedures}

The samples were cleaned by an ultrasonic cleaner and dehydrated by anhydrous ethanol. The microstructure and composition of Argopecten irradians was explored through X-ray diffraction (XRD), field emission scanning electron microscope (FESEM) and energy spectrometer (EDS). In order to investigate the effect of heat treatment temperature on the mechanical properties of Argopecten irradians, Argopecten irradians shell was heated 30min at different temperatures. The nanohardness and elastic modulus were measured using a nanoindentation tester.

The indentation depth was $800 \mathrm{~nm}$, the pressure speed was $10 \mathrm{~nm} / \mathrm{s}$, and the maximum load was $10 \mathrm{mN}$. There were 10 sampling points on each sample. By using the friction and wear test machine, the samples were tested against Si3N4 ball (a diameter of $4 \mathrm{~mm}$ ), as shown in Fig.1. Friction load was $1 \mathrm{~N}$ and $3 \mathrm{~N}$. Reciprocating frequency was $2 \mathrm{~Hz}$. Reciprocating distance was $2 \mathrm{~mm}$. Test time was 30 minutes. In the process of water-lubricated friction, deionised water was dropped in the friction surface as a lubricating medium. 


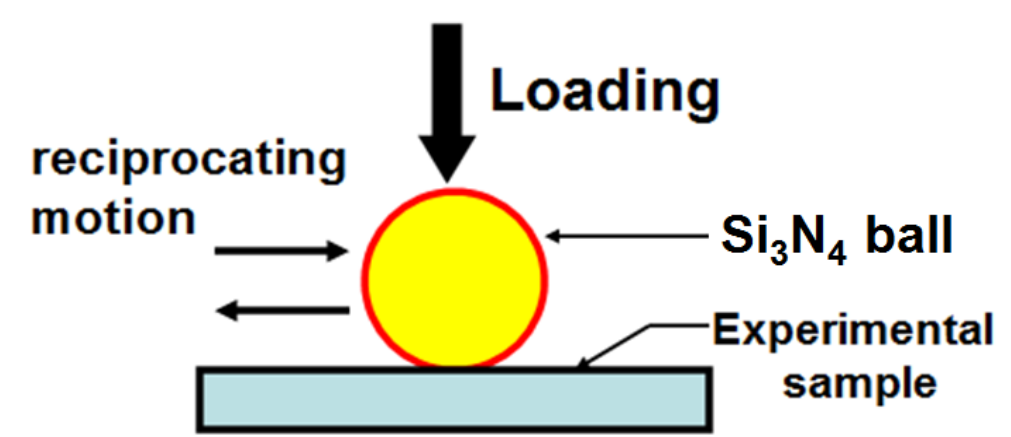

Fig.1. Schematic diagram of wear testing machine

\section{Results and discussions}

Surface morphology

Fig.2 shows the surface morphology of Argopecten irradians, and the striped texture features were very obvious. The shell was $7.7-8 \mathrm{~cm}$ in length and $400 \mu \mathrm{m}-1000 \mu \mathrm{m}$ in thickness. The left and right shells were approximately symmetrical. The number of radial ribs on the shell surface was $18-22$. The radial ribs were relatively smooth, about $500 \mu \mathrm{m}$ in height and generally $2-5 \mathrm{~cm}$ in width. The distance between the radial ribs was generally 2-4 cm.

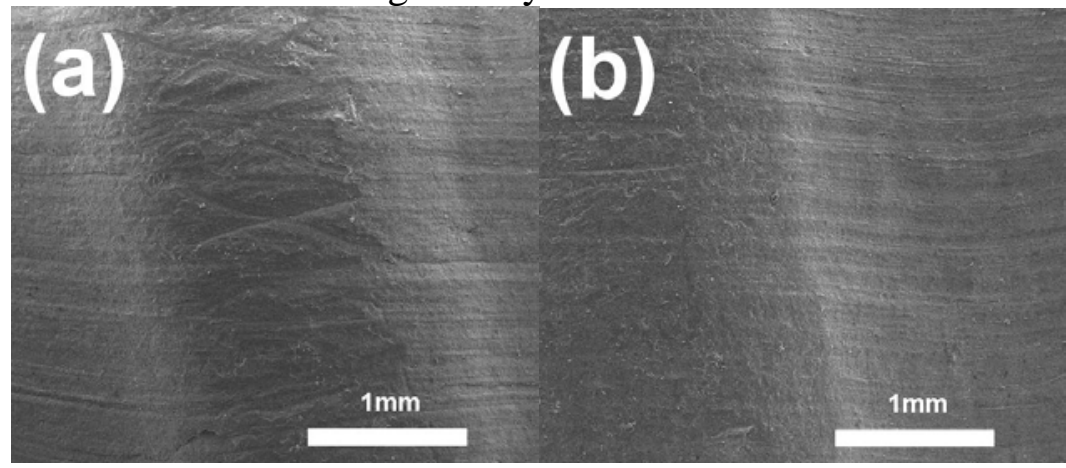

Fig.2. Radial ribs of Argopecten irradians shell

\section{Microstructure}

Fig.3 shows that the microstructure of Argopecten irradians shell was crossbeded. The lamellar microstructure was similar to layered tiles, and was composed by laminas connected of organic collagen. The thin plate had a variety of shapes, sizes and arrangements. Part of the thin plates had a winding shape, and raised the bonding interface between the thin plate and the organic matter. When the shell was broken, it was not easy to pull out from the matrix for the thin plate, and the resistance of the thin plate in the shell increased, which improved the fracture toughness of the shell.

The structure was composed of straight thin plates, which had a diameter of about several tens of nanometers and also varied. It has been found that the thin plates were not completely parallel and some had a conical shape. Every thin plate had its own orientation, so there was a fixed angle between the orientations of each region. When the angle was 90 degrees, it could be called "orthogonal arrangement". When the angle was less or greater than 90 degrees, it could be called "oblique arrangement". In light of this, it can be seen that the arrangement method of Argopecten irradians shell was mainly based on "orthogonal arrangement" and "oblique arrangement". This kind of arrangement method was in favour of increasing the resistance of pulling out lamellas, and further improved the fracture toughness of the shell. The microstructure of Argopecten irradians shell not only improved the fracture toughness, but also improved the wear resistance and anti-fatigue property. 


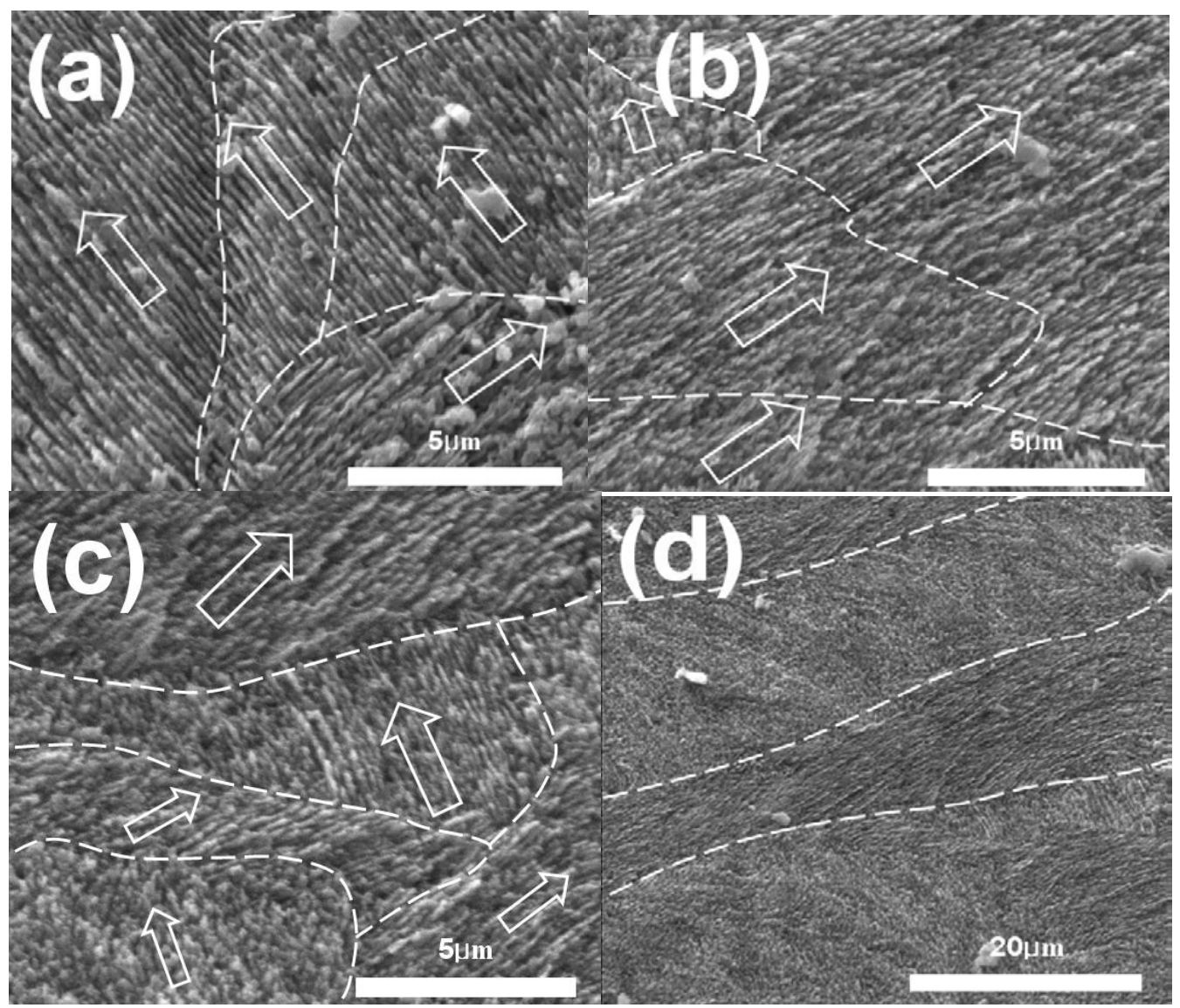

Fig.3. The sectional microstructure of Argopecten irradians shell

The EDS result of Argopecten irradians powder is shown in Fig.4. It can be seen that the main elements are calcium, carbon and oxygen. From the XRD results in Fig.5, we can know that the main chemical composition of Argopecten irradians is calcium carbonate $\left(\mathrm{CaCO}_{3}\right)$.

Fig.5 shows the XRD patterns of the inner layer, middle layer and outer layer. From the intensity and position of the peaks in the graph, it can be analysed that Argopecten irradians shell was composed of aragonite calcium carbonate in the three layers. Although the XRD patterns of the three layers were different, calcium carbonate of the XRD characterisation of the three layers was mainly aragonite. The results of the XRD analysis were in consonance with the microstructure of Argopecten irradians (Fig.3).

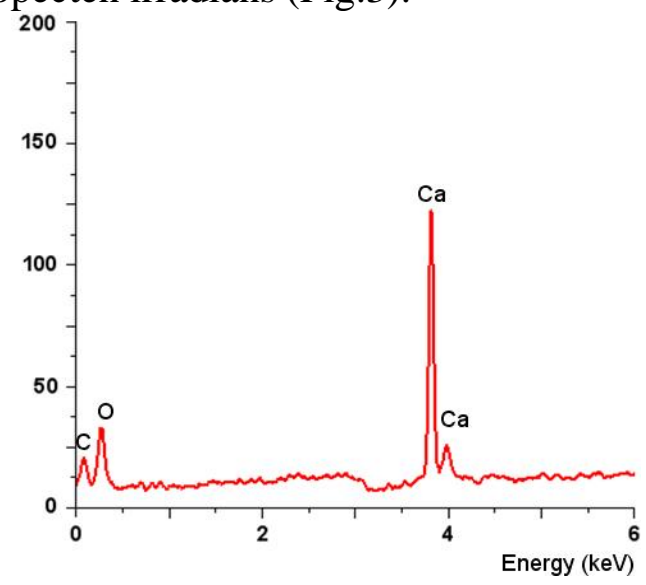

Fig.4. EDS analysis result of Argopecten irradians

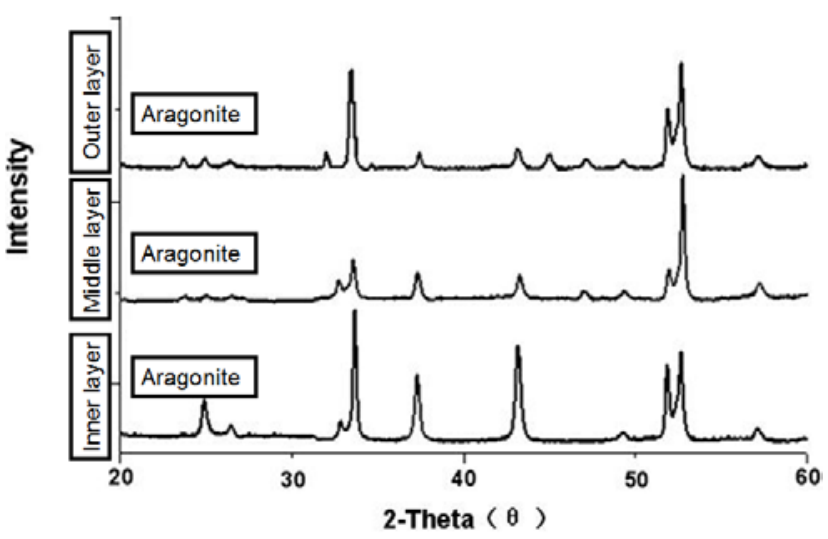

Fig.5. XRD analysis result of Argopecten irradians

Mechanical properties

The mechanical properties of biological materials were anisotropic owing to their microstructure. Fig.6 shows that the mechanical properties of Argopecten irradians surface were different from inside to outside. Its hardness and elastic modulus showed a clear gradient. Even in the same layer, the hardness and elastic modulus of Argopecten irradians had big fluctuations. The average elastic 
moduli of the outer and inner layers of Argopecten irradians were $5.85 \mathrm{GPa}$ and $1.08 \mathrm{GPa}$, respectively. The average hardness of the outer and inner layers of Argopecten irradians was 0.094 $\mathrm{GPa}$ and $0.017 \mathrm{GPa}$, respectively. It is indicated that the average hardness of the outer layer of Argopecten irradians was 5.5 times higher than the inner layer's, and there was a great difference in the mechanical properties of the outer and inner layers. The major reason for the difference of the mechanical properties was the gradient of calcium content in the outer and inner layers.
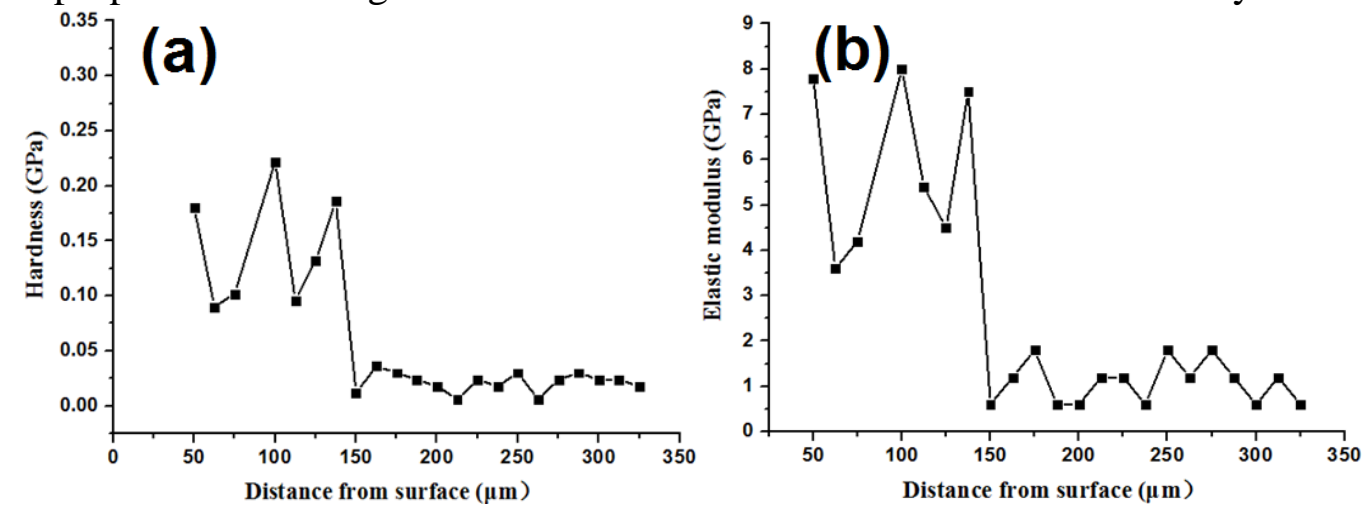

Fig.6. The hardness and elastic modulus of Argopecten irradians shell along depth direction

The Argopecten irradians shell was mainly composed of calcium carbonate and organic matter. Its content of moisture and organic matter gradually decreased with an increase in temperature. At the same time, the mechanical properties of the shell also changed. When the temperature was below $200^{\circ} \mathrm{C}$, the hardness curve of Argopecten irradians was fluctuating, as shown in Fig.7. When the temperature was greater than $200^{\circ} \mathrm{C}$, the hardness and elastic modulus of Argopecten irradians showed an increasing trend. The hardness and elastic modulus of Argopecten irradians shell at $250^{\circ} \mathrm{C}$ increased by 43 percent and 26 percent, respectively, comparing to the room temperature. It is suggested that the content of moisture and organic matter of Argopecten irradians shell had a strong influence on its mechanical properties
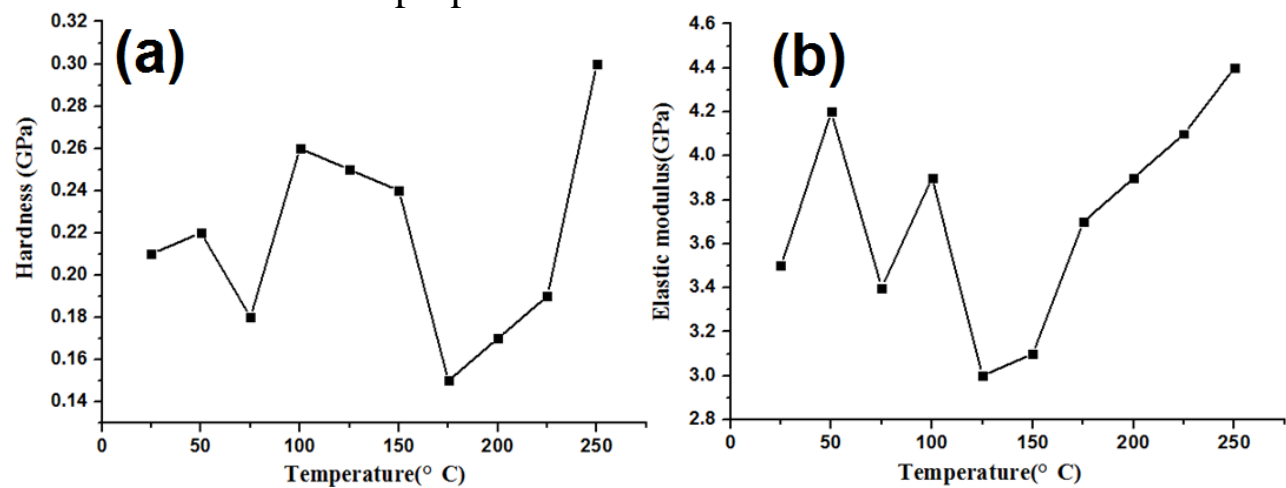

Fig.7. The hardness and elastic modulus of Argopecten irradians shell at different temperature Frictional properties

Fig.8 shows the effect of load on the frictional behaviour of Argopecten irradians shell $/ \mathrm{Si}_{3} \mathrm{~N}_{4}$ ball under dry and water-lubricated conditions. As shown in Fig.8, all of the frictional coefficients were fluctuating at the beginning of the test. In dry friction conditions, the frictional coefficient decreased with an increase in load $\left(\mu_{1 \mathrm{~N}}>\mu_{3 \mathrm{~N}}\right)$. In water-lubricated conditions, the friction coefficients were unstable, while the frictional coefficient decreased with an increase in load in general $\left(\mu_{1 \mathrm{~N}}>\mu_{3 \mathrm{~N}}\right)$. Under dry friction conditions, when the load was $1 \mathrm{~N}$, the frictional coefficient hovered around 0.12, and shallow wear scars appeared on the shell surface. Under water-lubricated conditions, when the load was $1 \mathrm{~N}$, the frictional coefficient hovered around 0.82, and the wearout phenomenon appeared on the shell surface. The variation of the frictional coefficient of dry friction was much greater than that of water-lubricated friction. There was not a big difference between the two kinds of conditions within the test time of 500s. However, with an increase in friction time, the frictional coefficient of the water-lubricated condition increased rapidly due to the occurrence of hydration reaction, which caused the "wearout phenomenon" and the change in the wear mechanism of the shell surface layer. 


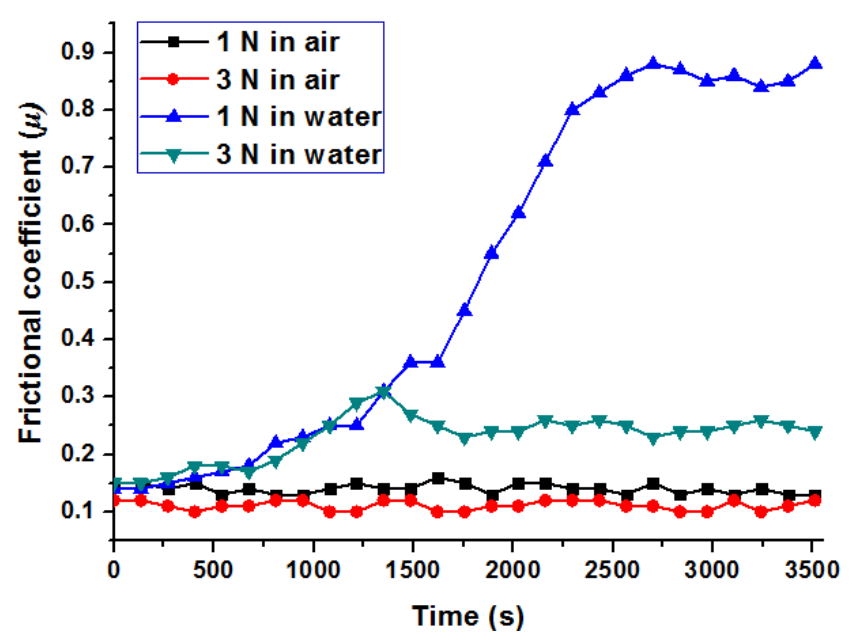

Fig.8. The effect of load on the frictional properties of Argopecten irradians shell /Si3N4 ball under dry and water lubricated conditions

The anisotropic characteristics of the microstructure of shell made Argopecten irradians have higher mechanical properties and better wear resistance in order to adapt to changed environments. Such a kind of biological structure improved the energy absorption of materials, so it could prevent the crack from initiating and propagating on shell surface. For biological materials, water played a role in toughening agent in the interior biomaterials. Once the water was evaporated, the biological material would lose its elasticity. Therefore, with an increase in heat treatment temperature, the water content of Argopecten irradians shell decreased, which led to a decrease in toughness, an increase in the hardness and elastic modulus. As shown in Fig.7, the frictional coefficient of the water-lubricated condition was relatively stable, and the frictional coefficient of water-lubricated friction was greater than that of dry friction owing to the hydration reaction at the friction interface.

\section{Conclusions}

This paper has investigated the microstructure and friction behaviour of Argopecten irradians shell. According to the analyses, the following conclusions are drawn:

1) The surface morphology of Argopecten irradians shell was radial ribs. Its microstructure had anisotropy.

2) The surface hardness and elastic modulus of Argopecten irradians shell were 0.094 and 5.85GPa, respectively. The hardness and elastic modulus of the shell gradually decreased with an increase in cross-section distance. The gradient change of the mechanical properties of the shell was obvious. When the heat treatment temperature was lower than $200^{\circ} \mathrm{C}$, the hardness and elastic modulus of shell changed a little at first, and then gradually increased.

3) In the frictional test of Argopecten irradians shell / $\mathrm{Si}_{3} \mathrm{~N}_{4}$ ball, the frictional coefficient of water lubricated condition was greater than that of dry friction.

\section{Acknowledgement}

The authors would like to acknowledge the Project Doctor Scientific Research Startup Fund (No.2012.301) and the Project Seed Fund (No.2015.247) of Jilin Agricultural Science and Technology College, the Scientific Research Program Project of Jilin Provincial Education Department (JiJiaoKeHeZi.2015.No.378) , the Project Youth Scientific Research Fund (No.20150520107JH) of Jilin Province Science and Technology Development Program for financial support.

\section{References}

[1] Xian Jia, Xiaomei Ling, Donghai Tang. Microstructures and friction-wear characteristics of bivalve shells [J]. Tribology International, 2006 39(7)657-662. 
[2] Limei Tian, Ximei Tian, Yinci Wang. Anti-wear properties of the molluscan shell Scapharca subcrenata: Influence of surface morphology, structure and organic material on the elementary wear process [J]. Materials Science and Engineering: C, 2014 (42)7-14.

[3] R. Arvind Singh, L. Siyuan, N. Satyanarayana. Bio-inspired polymeric patterns with enhanced wear durability for microsystem applications [J]. Materials Science and Engineering: C, 2011 31(7)1577-1583.

[4] Jin Tong, Mohammad Almagzoub Mohammad, Jinbo Zhang. DEM Numerical Simulation of Abrasive Wear Characteristics of a Bioinspired Ridged Surface [J]. Journal of Bionic Engineering, $20107(2) 175-181$.

[5] Philippe Stempflé, Marcel Brendlé. Tribological behaviour of nacre-Influence of the environment on the elementary wear processes [J]. Tribology International, 2006 39(12)1485-1496. 